\title{
The Prevalence of Aeromonas Species in Feces of Horses with Diarrhea
}

\author{
Terri L. Hathcock, John Schumacher, James C. Wright, and Joyce Stringfellow
}

\begin{abstract}
Feces collected from 40 horses with diarrhea and 34 horses without diarrhea were examined to determine if an association existed between isolation of Aeromonas spp. and diarrhea. Samples were also examined for Salmonella spp., and identification of viruses and parasite ova. Neither Salmonella spp. nor Aeromonas spp. were isolated from the feces of 34 control horses. Aeromonas spp. were isolated from feces of 22 of $40(55 \%)$ horses with diarrhea. Salmonella spp. were isolated from feces of $8(20 \%)$ horses, and of these, $5(12.5 \%)$ were also positive for Aeromonas spp. Twenty-nine isolates of Aeromonas spp. were recovered from the feces of 22 diarrheic horses. Of these isolates, more than $80 \%$ were susceptible on in vitro testing to amikacin, ceftiofur, chloramphenicol, and gentamicin. All isolates were susceptible to enrofloxacin. Diarrheic horses positive for Aeromonas were significantly $(P=.04)$ older than diarrheic horses negative for Aeromonas spp. A significantly greater number of fecal samples were positive for Aeromonas spp. during March through August than samples examined in other months $(P=.014)$. Results of this study indicate that Aeromonas spp. should be considered as a cause of diarrhea in horses.
\end{abstract}

Key words: Clostridia; Colitis; Enteritis; Salmonella.

$\mathbf{I}^{\mathrm{n}}$ nvestigations into the etiology of diarrhea in horses are often restricted to confirmation or exclusion of salmonellosis. ${ }^{1}$ Other bacteria recognized or suspected to cause diarrhea in horses or foals include Clostridium spp., ${ }^{2-4}$ Campylobacter spp., ${ }^{5,6}$ Escherichia coli, ${ }^{7-9}$ Streptococcus durans, ${ }^{8,10}$ Bacteroides fragilis, ${ }^{11}$ Actinobacillus equuli, ${ }^{5}$ Mycobacterium paratuberculosis, ${ }^{12-14}$ Aeromonas hydrophila ${ }^{5,8,15}$ Rhodococcus equi, ${ }^{16}$ and Klebsiella pneumoniae. ${ }^{17}$

Whether or not these bacteria are an important cause of diarrhea in the horse is unknown because of difficulties in isolation or because some may be part of the intestinal flora of normal horses. The prevalence of Aeromonas spp. in the gastrointestinal tract of horses, particularly in association with disease, is unknown. Aeromonas spp. may be a cause of diarrhea in foals, based on isolation of $A$. hydrophila from feces of two 3-day-old diarrheic foals. ${ }^{8}$ Isolation of A. hydrophila from enteric lesions of horses lead to speculation that this organism was a potential enteric equine pathogen. ${ }^{5}$ During a 2-year prospective study of diarrheic foals in Britain and Ireland, A. hydrophila was isolated from the feces of 9\% (28/ 304) of the diarrheic foals. ${ }^{15}$ A. hydrophila was associated with diarrhea and septic arthritis in a 4-day-old foal. ${ }^{18}$

Aeromonas spp. are gram-negative rods commonly found in water and soil. The genus Aeromonas is composed of at least 12 recognized species, each representing distinct DNA homology groups. In addition, there are several species of questionable validity and a number of unnamed DNA hybridization groups. ${ }^{19,20}$ Members of this genus have long been recognized as pathogens of fish and reptiles. ${ }^{21}$ Aeromonas spp. cause gastrointestinal and soft tissue infections in immunocompetent humans and disseminated infections in immunocompromised humans..$^{22,23}$ Aeromonas spp. are

From the Departments of Pathobiology (Hathcock, Wright, Stringfellow) and Large Animal Medicine and Surgery (Schumacher), College of Veterinary Medicine, Auburn University, Auburn, AL.

Reprint requests: Terri L. Hathcock, MS, Department of Pathobiology, College of Veterinary Medicine, Auburn University, Auburn, AL 36849; e-mail: hathctl@vetmed.auburn.edu.

Received May 8, 1998; Revised December 18, 1998; Accepted January 12, 1999.

Copyright (C) 1999 by the American College of Veterinary Internal Medicine

0891-6640/99/1304-0011/\$3.00/0 recovered from feces of humans with diarrhea more commonly than from feces of asymptomatic humans. ${ }^{24,25}$ Aeromonas probably causes diarrhea in humans by adherence to mucosa and elaboration of toxins. ${ }^{26,27}$ Known risk factors for disease in humans include swimming in or drinking untreated water and antimicrobial therapy with agents that are ineffective against aeromonads. ${ }^{24}$

From May 1993 through September 1995, 56\% of 110 fecal samples from horses with diarrhea examined for enteric bacterial pathogens in our laboratory were positive for Aeromonas spp. Consequently, an investigation was undertaken to determine the prevalence of aeromonads in feces from healthy and diarrheic horses and the possible association between isolation of Aeromonas spp. and diarrhea in horses. Feces from horses with diarrhea were also examined for the presence of Salmonella spp., viruses, and parasite ova.

\section{Materials and Methods}

\section{Horses}

Feces were collected from 40 horses presented to our hospital from April 8, 1996, through April 17, 1997, for treatment of diarrhea. For most horses with diarrhea, feces were collected from an age- and sexmatched control horse examined at our hospital for reasons other than gastrointestinal disease. Feces from horses with diarrhea and from control horses were used for bacterial, parasite, and viral studies. Feces from control horses were not always available at the time of examination of diarrheic feces; in most instances, control feces were obtained within 1 month. For 6 horses, a matched control was not available. Information concerning signalment, duration of diarrhea, and drug treatment before and after onset of diarrhea was recorded for each clinical case.

\section{Bacteriologic Studies}

Approximately $5 \mathrm{~g}$ of feces was collected in sterile specimen cups at the time of admission from all diarrheic and control horses. Samples were processed for isolation of Aeromonas and Salmonella spp. using standard bacteriologic techniques. Specimens were cultured aerobically onto trypticase soy blood agar (Difco Laboratories, Detroit, MI) with $5 \%$ bovine blood, MacConkey agar (Becton Dickinson, Sparks, MD), Hektoen Enteric agar (Oxoid, Ogdensburg, NY), SalmonellaShigella agar (Oxoid), and Cefusoldin-Irgansan-Novobiocin agar (Difco). All plate media, except for the blood agar, were incubated at $37^{\circ} \mathrm{C}$ under ambient conditions. Blood agar plates were incubated at $37^{\circ} \mathrm{C}$ with $10 \% \mathrm{CO}_{2}$. In addition, a $1 \%$ alkaline peptone broth was 
inoculated for Aeromonas spp. enrichment, and tetrathionate broth (Difco) was inoculated for Salmonella spp. enrichment. These broths were incubated at $28^{\circ} \mathrm{C}$ and $37^{\circ} \mathrm{C}$ in air, respectively. Isolates suggestive of Salmonella and Aeromonas spp. and any atypical fecal isolate were examined using standard methods. ${ }^{19,28}$ Definitive results of suspect Salmonella spp. were performed using an automated microidentification system (bioMerieux Vitek, Hazelwood, MO) and serologic methods. Oxidase-positive, gram-negative rods were screened for Aeromonas spp. using a $1 \%$ glucose broth containing a Durham tube for determination of gas production during glucose fermentation. Species were identified using conventional biochemical tests. ${ }^{29}$

\section{Antimicrobial Susceptibilities}

Disk diffusion assays on Mueller-Hinton agar (Difco) were employed to determine the antimicrobial susceptibility profile of each Aeromonas isolate. The methodology used to perform and interpret these tests was in accordance with the guidelines of the National Committee for Clinical Laboratory Standards (NCCLS). ${ }^{30}$ After 16-18 hours of incubation, the plates were examined and zone margins were selected as the areas showing no visible growth. The sizes of the zones were interpreted using published standards and the isolates reported as either susceptible, intermediate, or resistant to the agents tested. Because interpretative criteria have not been established for Aeromonas spp., NCCLS standards for members of the family Enterobacteriaceae were used. The antimicrobials tested were amikacin, ampicillin, amoxicillin-clavulanic acid, ceftiofur, cefoxitin, cephalothin, chloramphenicol, enrofloxacin, erythromycin, gentamicin, trimethoprimsulfamethoxazole, tetracycline, and ticarcillin.

\section{Parasitology}

Feces from all diarrheic horses and 8 control horses were examined for parasite ova by centrifugal fecal floatation using a sugar solution. Positive specimens were further examined using a modified Wisconsin sugar floatation method..$^{31,32}$ Numbers of ova, cysts, or oocysts were reported per $3 \mathrm{~g}$ of feces.

\section{Viral Studies}

Fresh fecal samples from all diarrheic horses were frozen at $-80^{\circ} \mathrm{C}$ and later analyzed for presence of enteric viruses. Feces were examined for rotavirus using the Rotaclone Rotavirus Enzyme Immunoassay (EIA) test kit (Cambridge Biotech Corp, Worcester, MA) according to the manufacturer's instructions. Samples were examined for coronavirus by electron microscopy (Philips 301 transmission electron microscope, FEI Company, Hillsboro, OR) using negative staining with phosphotungstic acid at a magnification of $34,000 \times$. A specimen was considered positive if 6 or more particles with peplomeric surface structures characteristic of a coronavirus were observed. Feces from 5 control horses were examined as negative controls for the Rotaclone Rotavirus EIA and electron microscopy.

\section{Data Analysis}

Data were analyzed using Statistical Analysis System (SAS release version 6.03) and EpiInflo (release version 6.04b) software. The relationship between age and isolation of Aeromonas spp. from horses with diarrhea was analyzed using the Wilcoxon rank-sum test. ${ }^{33}$ The association of different variables such as antibiotic use, presence of diarrhea, and parasite isolation with isolation of Aeromonas spp. was assessed using the chi-square test for independence or Fisher's exact test. Probabilities lower than .05 were considered significant.

\section{Results}

The incidence of Aeromonas and Salmonella spp. from horses with diarrhea and from age- and-sex-matched horses
Table 1. Prevalence of Aeromonas and Salmonella species in horses with diarrhea and from age- and sex-matched control horses without diarrhea.

\begin{tabular}{lcc}
\hline \multicolumn{1}{c}{ Category } & $\begin{array}{c}\text { Horses with } \\
\text { Diarrhea }(\%)\end{array}$ & $\begin{array}{c}\text { Control } \\
\text { Horses }\end{array}$ \\
\hline Total & 40 & 34 \\
Aeromonas only & $17(42)$ & 0 \\
Salmonella only & $3(8)$ & 0 \\
Both Aeromonas and Salmonella & $5(12)$ & 0 \\
Negative & $15(38)$ & 34 \\
\hline
\end{tabular}

without diarrhea is shown in Table 1. Neither Salmonella spp. nor Aeromonas spp. were isolated from the feces of 34 control horses. Of 40 horses presented for diarrhea, Aeromonas spp. were isolated from feces of $22(55 \%, P<$ $.001)$. Salmonella spp. were isolated from feces of $8(20 \%)$ horses $(P<.01)$, and of these, $5(12.5 \%)$ also were positive for Aeromonas spp. Fecal samples from 18 (45\%) diarrheic horses were positive for intestinal parasites, 10 of which were also Aeromonas-positive. Seventeen (42.5\%) diarrheic horses had low numbers $(<100 \mathrm{ova} / \mathrm{g})$ of strongyle-type ova and $4(10 \%)$ were positive for Parascaris spp. ova. Feces from $3(37 \%)$ of the 8 control horses tested for intestinal parasites were positive for strongyle-type ova. A fecal sample from 1 (2.5\%) of the 40 horses with diarrhea was positive for rotavirus and feces from 4 (10\%) of the diarrheic horses were positive for coronaviruslike virus particles. Two diarrheic horses with feces positive for coronavirus also had a positive fecal culture for Aeromonas spp. Feces from 1 of 5 control horses examined was positive for coronavirus by electron microscopy.

All 22 horses that were Aeromonas-positive had diarrhea; however, only $35 \%$ of the Aeromonas-negative horses had diarrhea $(P<.0001)$. These findings were similar for $\mathrm{Sal}$ monella-positive and -negative horses. All of the horses that were Salmonella-positive had diarrhea, but $48 \%$ without Salmonella spp. also had diarrhea $(P=.0063)$. No association was found between the presence of strongyles and diarrhea in the horses tested $(P=1.0)$.

Twenty-nine isolates of Aeromonas were recovered from feces of 22 diarrheic horses. Feces of 7 horses were positive for more than 1 species of Aeromonas. Of the 29 isolates recovered, 16 (55\%) were identified as Aeromonas caviae, $9(31 \%)$ as A. hydrophila, $3(10 \%)$ as A. veronii-sobria, and $1(3 \%)$ Aeromonas isolate that could not be identified to species.

Diarrheic horses from which Aeromonas spp. were isolated were significantly $(P=.04)$ older than diarrheic horses from which Aeromonas spp. were not isolated (11 year median and 3 year median, respectively). No relationship was found between sex of horse and isolation of Aeromonas from the feces $(P>.05)$. A significant association $(P=$ .014) was found between season of year and the isolation of Aeromonas spp. Sixteen of $20(80 \%)$ horses with diarrhea examined from March through August were positive for Aeromonas spp. In comparison, only 6 of 20 (30\%) horses with diarrhea examined between September and February were positive for Aeromonas spp. 
Agar disk diffusion antimicrobial susceptibilities were performed on 29 isolates of Aeromonas. None of the isolates were susceptible to ampicillin or erythromycin. Less than $25 \%$ were susceptible to amoxicillin-clavulanic acid, cephalothin, trimethoprim-sulfamethoxazole, or ticarcillin. Of the 29 isolates, $56 \%$ were susceptible to cefoxitin and $76 \%$ were susceptible to tetracycline. More than $80 \%$ of the strains were susceptible to amikacin, ceftiofur, chloramphenicol, and gentamicin. All isolates were susceptible to enrofloxacin. A. caviae isolates were more resistant to the selection of antimicrobials tested than were isolates of A. hydrophila and A. veronii-sobria. The 1 Aeromonas isolate that could not be identified to species was found to have the greatest degree of resistance; this isolate was susceptible only to amikacin, enrofloxacin, and gentamicin.

Clinical signs of respiratory disease were reported for 6 Aeromonas-positive horses at the onset of diarrhea. Gastrointestinal sand was thought to be the initiating cause of diarrhea in 2 Aeromonas-positive horses. Hospitalization, Cushing's disease, injury, septic peritonitis, or probable gastric ulceration occurred before the onset of diarrhea in 9 Aeromonas-positive horses. A possible initiating cause of diarrhea was not determined for 6 Aeromonas-positive horses $(27 \%)$.

Only 2 Aeromonas-positive horses were presented with chronic diarrhea (more than 10 days duration). These horses had diarrhea for approximately 3 weeks at the time of euthanasia or death. Aeromonas-positive horses were often neutropenic $\left(<3 \times 10^{3}\right.$ cells $\left./ \mu \mathrm{L}\right)(8 / 17$ horses, $47 \%)$, hypoproteinemic (serum total protein $<6 \mathrm{~g} / \mathrm{dL})(15 / 19$ horses, $79 \%)$, and azotemic $(>2.0 \mathrm{mg} / \mathrm{dL}$ serum creatinine or $>20 \mathrm{mg} / \mathrm{dL}$ serum urea nitrogen) (11/16 horses, 69\%). Ten of the 22 (45\%) Aeromonas-positive horses died or were euthanized and 5 of the $12(42 \%)$ Aeromonas-negative horses with diarrhea died or were euthanized $(95 \% \mathrm{CI}=$ $0.40<$ odds ratio $<2.45 ; P=.83$ ).

Antimicrobial drugs were administered to 9 of the 22 Aeromonas-positive (41\%) horses shortly before the onset of diarrhea for treatment of respiratory disease (4 horses), injury ( 2 horses), a septic joint, laminitis, and prophylactically for castration. Of these 9 Aeromonas-positive horses, 4 had fecal isolates of Aeromonas spp. that were resistant to the antimicrobial administered (trimethoprim-sulfa products in 3 horses and oxytetracycline in another). One horse treated with trimethoprim-sulfa products had fecal cultures from which both A. caviae and A. hydrophila were recovered and both isolates were resistant to the antibiotic upon laboratory testing. The Aeromonas-positive horse given oxytetracycline was necropsied and intestinal contents yielded many colonies of A. caviae and Salmonella sp., serogroup B. Two phenotypic strains of A. caviae were recovered from the feces of this horse and both strains of $A$. caviae and the Salmonella isolate were resistant to tetracycline. Of the 18 Aeromonas-negative, diarrheic horses, 3 received antibiotics before the onset of diarrhea (17\%); 2 received both procaine penicillin $\mathrm{G}$ and gentamicin, and the 3 rd was given trimethoprim-sulfa. No significant difference $(P=.19)$ was found in the previous use of antibiotics in Aeromonas-positive and Aeromonas-negative horses with diarrhea.

\section{Discussion}

This study supports the theory that Aeromonas spp. are a cause of diarrhea in horses because Aeromonas spp. were isolated only from diarrheic horses and not from ageand sex-matched controls. Furthermore, the isolation of Aeromonas spp. from $55 \%$ of horses with diarrhea was greater than isolation of Salmonella (20\%). The high isolation rate of Aeromonas spp. possibly could be attributed to the intestinal environment of horses with diarrhea that may support proliferation of this organism. The Aeromonas isolation rate $(55 \%)$ in this study is much higher than the $9 \%$ reported from diarrheic foals in Great Britain and Ireland. ${ }^{15}$ The difference in isolation rate between these 2 groups of diarrheic horses may be related to the differences in age of horses sampled, environment, or specimen handling.

Aeromonas spp. have been implicated increasingly as the cause of acute gastroenteritis in humans. ${ }^{27,34}$ In some populations, Aeromonas-induced diarrhea is thought to be the most common cause of bacterial gastroenteritis in humans; however, no well-documented outbreaks of Aeromonas-associated gastroenteritis are known..$^{27,35,36}$ In epidemiologic studies of human diarrhea, the rate of recovery of aeromonads from feces is usually much higher in patients with diarrhea than in those who are asymptomatic. ${ }^{34,35,37,38}$ In our study Aeromonas spp. were not isolated from the feces of 34 control horses; however, in another study, Aeromonas spp. were isolated from the feces of 7 of $108(6 \%)$ asymptomatic horses. ${ }^{39}$ This difference in Aeromonas isolation rates from asymptomatic horses may be related to the seasonal temperature at the time of sample collection. Aeromonads are isolated most commonly from the feces of both symptomatic and asymptomatic humans during the warmest months of the year. ${ }^{37,38}$ Because this study was conducted over 12 months, feces of control and diarrheic horses were examined during both warm and cold months. In the earlier survey, ${ }^{39}$ feces were collected during May through November, which coincides with the highest occurrence of Aeromonas spp. in drinking water. ${ }^{35,36,38}$ A correlation exists between isolation of $A$. hydrophila from animal feces and its presence in their drinking water. The prevalence of Aeromonas spp. in apparently healthy animals may reflect constant exposure to Aeromonas-contaminated water. ${ }^{40}$ Furthermore, prevalence of Aeromonas spp. in feces of symptomatic and asymptomatic humans shows geographical variation. ${ }^{36-38}$ The previous investigation was conducted in South Wales, this study was conducted in the southeastern United States.

Based on the data from this study, Aeromonas spp. may be associated with diarrhea in horses. Although a connection between the strain of Aeromonas cultured from feces and the drinking water source could not be made from the data collected during this study, drinking water should be examined as a potential source of Aeromonas spp. in diarrheic horses. Furthermore, challenge studies are also warranted to determine if previous exposure to antibiotics, with and without contaminated water, is a risk factor for gastrointestinal infection with Aeromonas spp. in the horse. 


\section{Acknowledgments}

We wish to acknowledge the invaluable technical assistance of Brenda Bixler, Maria Tovio-Kinnucan, and Krystyna Minc. This research was supported by a grant from the American Horse Show Association.

\section{References}

1. Roberts MC. Acute equine colitis: Experimental clinical perspectives. In: Grunsell CSG, Raw ME, eds. Veterinarians Annual, 30th ed. Boston, MA: Butterworth \& Co; 1990:1-11.

2. Jones RL, Adney WS, Alexander AF, et al. Hemorrhagic necrotizing enterocolitis associated with Clostridium difficile infection in four foals. J Am Vet Med Assoc 1988;193:76-79.

3. Wierup M. Equine intestinal clostridiosis. An acute disease of horses associated with high intestinal counts of Clostridium perfringens type A. Acta Vet Scand Suppl 1977;62:1-82.

4. Prescott JF, Staempfli HR, Barher LK, et al. A method of reproducing fatal idiopathic colitis (colitis $\mathrm{X}$ ) in ponies and isolation of a clostridium as a possible agent. Equine Vet J 1988;20:417-420.

5. Al-Mashat RR, Taylor DJ. Bacteria in enteric lesions of horses. Vet Rec 1986;118:453-458.

6. Atherton JG, Ricketts SW. Campylobacter infection from foals. Vet Rec 1980;17:264-265.

7. Tzipori S, Withers M, Robbins-Browne, et al. Attachment of $E$. coli-bearing K88 antigen to equine brush-border membranes. Vet Microbiol 1984;9:561-570.

8. Tzipori S. The relative importance of enteric pathogens affecting neonates of domestic animals. Adv Vet Sci Comp Med 1985;29:103206.

9. Ansuini A, Candotti P, Vecchi G, et al. Neurotoxigenic E. coli in rabbits and horses. Vet Rec 1994;134:608.

10. Tzipori S, Hayes J, Sims L. Streptococcus durans: An unexpected enteropathogen of foals. J Infect Dis 1984;150:589-593.

11. Meyers LL, Shoop DS, Byars TD. Diarrhea associated with enterotoxigenic Bacteriodes fragilis in foals. Am J Vet Res 1987;48: $1565-1567$.

12. Larson AB, Moon HW, Merkal RS. Susceptibility of horses to Mycobacterium paratuberculosis. Am J Vet Res 1972;33:2185-2189.

13. Buergelt CD, Green SL, Mayhew IG, et al. Avian mycobacteriosis in three horses. Cornell Vet 1988;78:365-380.

14. Merritt AM, Merkal RS, Skye D, et al. A case of avian tuberculosis in the intestinal tract of a horse. Dig Dis 1975;20:598.

15. Browning GF, Chalmers RM, Snodgrass RM, et al. The prevalence of enteric pathogens in diarrhoeic Thoroughbred foals in Britain and Ireland. Equine Vet J 1991;23:405-409.

16. Cimprich RE, Rooney JR. Corynebacterium equi enteritis in foals. Vet Pathol 1980;14:95-102.

17. Kamada M, Senba H, Ohishi H, et al. Isolation of Klebsiella pneumoniae, capsule type 1 from foals with diarrhea in a horse breeding area of Japan. Bull Equine Res Inst 1985;22:43-47.

18. Traub-Dargatz JL, Schlipf JW Jr, Atwell E, et al. Aeromonas hydrophila septic arthritis in a neonatal foal. Equine Pract 1994;16: $15-17$.

19. Janda JM, Abbott SL, Carnahan AM. Aeromonas and Plesiomonas. In: Murray PR, Barron EJ, Pfaller MA, et al, eds. Manual of Clinical Microbiology, 6th ed. Washingtion, DC: American Society for Microbiology; 1995:477-482.

20. Borrell N, Acinas SG, Figueras M, et al. Identification of Aeromonas clinical isolates by restriction fragment length polymorphism of PCR-amplified 16S rRNA genes. J Clin Microbiol 1997;35:16711674.

21. Popoff M. Genus III. Aeromonas. Kluyver and van Niel 1936, 398. In: Krieg NR, Holt JG, ed. Bergey's Manual of Systematic Bacteriology, 9th ed, Vol 1. Baltimore, MD: The Williams \& Wilkins Co; 1984:545-548.

22. Atwegg M, Geiss HK. Aeromonas as a human pathogen. CRC Crit Rev Microbiol 1989;16:253-286.

23. Janda JM, Duffy PS. Mesophilic aeromonads in human disease: Current taxonomy, laboratory identification, and infectious disease spectrum. Rev Infect Dis 1988;10:980-997.

24. Moyer NP. Clinical significance of Aeromonas species isolated from patients with diarrhea. J Clin Microbiol 1987;25:2044-2048.

25. Holmberg SD, Schell WL, Fanning GR, et al. Aeromonas intestinal infections in the United States. Ann Intern Med 1986;105:683689.

26. Shaw J, Thornley J, Eley A. Adherance and invasion of Aeromonas caviae to monolayer cells. In: Paul P, Francis D, Benfield D, ed. Mechanisms in the Pathogenesis of Enteric Diseases. New York, NY: Plenum Press; 1997:217-219.

27. Namdari H, Bottone EJ. Microbiologic and clinical evidence supporting the role of Aeromonas caviae as a pediatric enteric pathogen. J Clin Microbiol 1990;28:837-840.

28. Farmer JJ. Enterobacteriaceae: Introduction and Identification. In: Murray PR, Baron EJ, Pfaller MA, et al, eds. Manual of Clinical Microbiology, 6th ed. Washington, DC: American Society for Microbiology; 1995:438-449.

29. Abbott SL, Cheung WK, Kroske-Bystrom S, et al. Identification of Aeromonas strains to the genospecies level in the clinical laboratory. J Clin Microbiol 1992;30:1262-1266.

30. NCCLS. Performance standards for antimicrobial disk and dilution susceptibility tests for bacteria isolated from animals; proposed standard. NCCLS Document M31-P. Villanova, PA: 1994.

31. Bliss DH, Jones RM, Conder DR. Epidemiology and control of gastrointestinal parasitism in lactating, grazing adult dairy cows using a morantel sustained release bolus. Vet Rec 1982;110:141-144.

32. Bliss DH, Kvasnicka WG. The fecal examination: A missing link in food animal practice. Compend Cont Educ Pract Vet Food Anim Med Manage 1997;(Suppl):104-109.

33. Zar JH. Biostatistical Anaylsis, 2nd ed. Englewood Cliff, NJ: Prentice-Hall, Inc; 1984:138, 390-395.

34. Deodhar LP, Saraswathi K, Varudkar A. Aeromonas spp. and their association with human diarrheal disease. J Clin Microbiol 1991; 29:853-856.

35. Burke V, Gracey M, Robinson J, et al. The microbiology of childhood gastroenteritis: Aeromonas species and other infective agents. J Infect Dis 1983;148:68-74.

36. Moyer NP. Clinical significance of Aeromonas species isolated from pediatric patients with diarrhea. J Clin Microbiol 1987;25:20442048.

37. Gracey M, Burke V, Robinson J. Aeromonas-associated gastroenteritis. Lancet 1982;2:1304-1306.

38. Agger WA, McCormick JD, Gurwith MJ. Clinical and microbiological features of Aeromonas hydrophila-associated diarrhea. J Clin Microbiol 1985;21:909-913.

39. Gray SJ. Aeromonas hydrophila in livestock: Incidence, biochemical characteristics and antibiotic susceptibility. J Hyg 1984;92: 365-375.

40. Gray SJ, Stickler DJ. Some observations on the fecal carriage of mesophilic Aeromonas species in cows and pigs. Epidemiol Infect 1989;103:523-537. 